\title{
Doces cristalizados de frutas produzidos em Pelotas-RS com potencial de obtenção do selo de Indicação de Procedência (IP): um estudo de caso
}

\author{
Laís Rössler Rech, Mírian Ribeiro Galvão Machado
}

https://doi.org/10.4322/mp.978-65-991393-5-2.c5

\section{Resumo}

A cidade de Pelotas-RS é reconhecida como patrimônio cultural brasileiro devido as suas tradições doceiras na produção de doces tradicionais de confeitaria e cristalizados. Detém a Associação Doce Pelotas que protege o legado das tradições doceiras e possui o registro de Indicação Geográfica (IG) dispondo do selo de Indicação de Procedência (IP) para 15 variações de doces. O objetivo deste trabalho foi avaliar o potencial de obtenção de Selo de Indicação de Procedência (IP) de cristalizados de fruta produzidos na cidade de Pelotas-RS. Foram aplicados à empresas produtoras questionários com temas referentes à participação na Associação Doce Pelotas, conhecimento e interesse na obtenção do selo IP. Assim, foram adquiridas amostras de figos cristalizados, as quais foram submetidas à análises físico-químicas e microbiológicas, com intuito de avaliar a conformidade destas com os parâmetros previstos na legislação. Nenhuma das três empresas produtoras de frutas cristalizadas pertence à Associação Doce Pelotas e consequentemente não dispõe do selo de Indicação de Procedência (IP). Quanto às análises físico-químicas e microbiológicas todas as amostras apresentaram-se dentro dos parâmetros exigidos pela legislação vigente. Os resultados mostraram que, apesar de não participarem da Associação e nem possuírem o selo IP, os doces de figo cristalizados produzidos por doceiras locais, e analisados neste trabalho, têm qualidade, cumprem os requisitos de boas práticas de fabricação e possuem potencial tecnológico para obtenção do selo de Indicação de Procedência (IP).

Palavras-chave: controle de qualidade, doces cristalizados de frutas, figo, tecnologia de doces.

\section{Introdução}

A cidade de Pelotas, localizada ao sul do Rio Grande do Sul, Brasil (latitude $31^{\circ} 46^{\prime}$ $19^{\prime \prime}$ S, longitude $52^{\circ} 20^{\prime} 33^{\prime \prime}$ W) é reconhecida pelo Instituto do Patrimônio Histórico e Artístico Nacional (Iphan) como Patrimônio Cultural Brasileiro, obtendo o certificado de reconhecimento do Conjunto Histórico de Pelotas e das Tradições Doceiras da Região de Pelotas e Antiga Pelotas (Arroio do Padre, Capão do Leão, Morro Redondo, Turuçu), no Rio Grande do Sul (INSTITUTO DO PATRIMÔNIO HISTÓRICO ARTÍSTICO E NACIONAL, 2018). 
Os famosos doces pelotenses, herança da colonização portuguesa, alemã e italiana, são responsáveis pelo desenvolvimento do setor doceiro que exporta as iguarias para diversas cidades do Brasil (CHIATTONE et al., 2012).

Com o objetivo de fortalecer o setor, proteger o legado das receitas de doces tradicionais e estimular a inovação e desenvolvimento das empresas produtoras dos doces, no ano de 2008, foi formalizada a Associação Doce Pelotas, que possui atualmente 17 doceiras associadas (ASSOCIAÇÃO DOS PRODUTORES DE DOCES DE PELOTAS, 2018).

A partir do ano de 2011 o Instituto Nacional de Propriedade Industrial (INPI) concedeu o registro de Indicação geográfica (IG) dispondo o selo de Indicação de Procedência (IP) para algumas variedades de doces produzidos na cidade de Pelotas.

A IG é um direito de propriedade industrial relacionado à reputação de um bem oriundo de um lugar geográfico ou de um bem que possua características específicas, essencialmente em função do meio geográfico no qual o mesmo se originou (PERALTA et al., 2016).

Conforme o artigo 177 da Lei $n^{\circ}$. 9279/96 considera-se indicação de procedência o nome geográfico de país, cidade, região ou localidade de seu território, que se tenha tornado conhecido como centro de extração, produção ou fabricação de determinado produto ou de prestação de determinado serviço (BRASIL, 1996).

A IP para doces tradicionais de confeitaria e de frutas está baseada nos quesitos: tradição, localidade e qualidade, conforme dados constantes no processo de requerimento do registro da IP junto ao INPI. É uma estrutura baseada no cumprimento de padrões, no registro de informações para rastreamento, garantia da tipicidade dos doces e segurança dos processos. Na indicação de procedência de Pelotas está autorizada a produção dos seguintes doces: Amanteigado, Beijinho de Coco, Bem Casado, Broinha de Coco, Camafeu, Fatias de Braga, Ninho, Olho-desogra, Papo de Anjo, Panelinha de Coco, Pastel de Santa Clara, Queijadinha, Quindim, Trouxa de Amêndoas e Doces Cristalizados de Frutas (SEBRAE, 2018).

De acordo com a Associação dos Produtores de Doces de Pelotas (2018), doces cristalizados de frutas são doces produzidos artesanalmente a partir de frutas e outros hortifrutigranjeiros, com açúcar por meio da ação do calor (fervura, secagem). Encontram-se nesta classificação: abóbora cristalizada, banana cristalizada, goiaba cristalizada, pessegada cristalizada, laranja cristalizada, figo cristalizado, marmelada, origone (pêssego seco), passa de pêssego.

Tais doces apresentam uma textura macia, tenra e com leve crocância na parte externa. Ressalta-se que não são permitidos os melhoradores de produtos que não estejam permitidos pela legislação para este tipo de produto, tais como anti-mofo, conservantes, aditivos, corantes, emulsificantes. Além disso, sua conservação varia dependendo do ambiente e tipo de embalagem na qual é armazenado (PERALTA et al., 2016).

Conceitualmente, fruta cristalizada é o produto preparado com frutas, atendendo as definições destes padrões, nas quais se substitui parte da água da sua constituição por açúcares, por meio de tecnologia adequada, recobrindo-as ou não com uma camada de sacarose (BRASIL, 1977).

Para obtenção do selo IP o produtor deverá ser membro da Associação dos Produtores de Doces de Pelotas, obedecer criteriosamente aos processos de 
produção estabelecidos, cumprir o regulamento técnico e submeter-se a constantes controles de qualidade para garantir a integridade da receita e do doce (ASSOCIAÇÃO DOS PRODUTORES DE DOCES DE PELOTAS, 2018).

O processo de reconhecimento da indicação de procedência para os doces de Pelotas promoveu uma padronização da produção dos doces entre os associados. Entre as contribuições, destacam-se a possibilidade de ter acesso à informação, a cursos, bem como às divulgações e às orientações sobre o próprio negócio. Como limitações, surgiram questões como a dificuldade de aceitação de ideias inovadoras, no que tange à confecção dos produtos, dadas as exigências referentes à padronização do tamanho do doce, o modus operandi de fabricação e as restrições de ingredientes dos doces (PERALTA et al., 2016).

Considerando o acima exposto, este estudo teve como objetivo avaliar o potencial de obtenção de Selo de Indicação de Procedência (IP) de frutas cristalizadas produzidas na cidade de Pelotas-RS, com base nos requisitos legais de qualidade.

\section{Materiais e Métodos}

Foram coletadas amostras de doce de figo cristalizado em três empresas produtoras, as quais foram submetidas às análises físico-químicas e microbiológicas, com intuito de avaliar a conformidade destas com os parâmetros previstos na legislação.

As análises de $\mathrm{pH}$, acidez total, umidade e sólidos solúveis foram realizadas, em triplicata, conforme técnicas de análises descritas nas Normas Analíticas do Instituto Adolfo Lutz (INSTITUTO ADOLFO LUTZ, 2008).

Todos os ensaios foram realizados no Laboratório de Análises Físico Químicas de Alimentos e Laboratório de Análises Microbiológicas, ambos do Centro de Ciências Químicas, Farmacêuticas e de Alimentos (CCQFA), UFPel.

\subsection{Análises físico-químicas}

\subsubsection{Determinação de pH (potenciometria)}

Determinado pela leitura direta em pHmetro (Quimis Q400as).

\subsubsection{Determinação de acidez total titulável}

Determinada através da titulação da amostra com $\mathrm{NaOH} 0,1 \mathrm{~mol} \cdot \mathrm{L}^{-1}$, até obtenção de coloração rósea permanente por 30 segundos. Resultado expresso em porcentagem de ácido cítrico.

\subsubsection{Determinação de umidade}

A umidade foi determinada por gravimetria, através de secagem direta em estufa à $105{ }^{\circ} \mathrm{C}$, com circulação de ar, com verificações esporádicas até obtenção de peso constante.

\subsubsection{Determinação de sólidos solúveis totais}

Determinada por leitura direta em refratômetro digital (ATAGO), com resultados expressos em ${ }^{\circ}$ Brix. 


\subsection{Análises microbiológicas}

Foram realizadas no Laboratório de Microbiologia de Alimentos, CCQFA, UFPel, em triplicata, as análises microbiológicas de Coliformes a $45^{\circ} \mathrm{C}$, Bolores e leveduras, Salmonella sp e Estafilococos coagulase positiva conforme metodologia descrita por SILVA et al. (2007).

\subsubsection{Contagem de Coliformes Termotolerantes pela Técnica de Número Mais Provável (NMP) e Confirmação de E. coli}

Foram pesadas $25 \mathrm{~g}$ da amostra, em condições assépticas, e homogeneizadas com $225 \mathrm{~mL}$ de água peptonada $0,1 \%$ (diluição $10^{-1}$ ). A partir desta, foram feitas diluições decimais seriadas, até $10^{-3}$. De cada diluição foram retirados $1 \mathrm{~mL}$ e inoculados em tubos contendo $9 \mathrm{~mL}$ Caldo Lauril Sulfato Triptose (CLST), com tubo de durhan invertido, em triplicata. Ao término do período de incubação, $37 \pm 1{ }^{\circ} \mathrm{C}$ por $48 \mathrm{~h}$, dos tubos de CLST positivos (com produção de gás), transferiu-se uma alçada para tubos contendo Caldo $E$. coli (EC) que foram incubados a $45,5 \pm 0,2{ }^{\circ} \mathrm{C}$ por $48 \mathrm{~h}$, em banhomaria. Após observou-se a ocorrência de crescimento e produção de gás, sendo realizada a leitura em tabela de NMP. A confirmação de E. coli, de cada tubo de EC positivo, foi realizada através de alçada por esgotamento, em placas contendo Ágar Eosina Azul de Metileno (EMB), incubadas à $37 \pm 1{ }^{\circ} \mathrm{C}$ por $24 \mathrm{~h}$, onde verificou-se 0 aparecimento de colônias típicas, ou seja, com centro negro, com ou sem brilho metálico.

\subsubsection{Contagem de Estafilococos Coagulase Positiva}

A partir das diluições anteriores foram semeados $0,1 \mathrm{~mL}$ em placas contendo Ágar Baird Parker (BP), em triplicata, e incubadas a $37 \pm 1{ }^{\circ} \mathrm{C}$ por $48 \mathrm{~h}$. Ao término do período foi realizada a contagem de colônias e expresso o resultado em unidades formadoras de colônias por grama (UFC $\mathrm{g}^{-1}$ ).

\subsubsection{Contagem de Bolores e Leveduras}

A partir das diluições anteriores foram semeados $0,1 \mathrm{~mL}$ em placas contendo Ágar Batata Dextrose (BDA), em triplicata. Incubou-se em estufa a $25 \pm 0,2{ }^{\circ} \mathrm{C}$ por 5 dias e fez se a contagem das colônias. O resultado, média das contagens, foi expresso em unidades formadoras de colônias (UFC. $\mathrm{g}^{-1}$ )

\subsubsection{Pesquisa de Salmonella sp.}

Foram pesadas assepticamente $25 \mathrm{~g}$ de amostra e homogeneizadas com $225 \mathrm{~mL}$ de Caldo Lactosado (CL), deixado em repouso por $1 \mathrm{~h}$ e após incubado a $37 \pm 1{ }^{\circ} \mathrm{C}$ por $18 \pm 2 \mathrm{~h}$. No enriquecimento seletivo transferiram-se alíquotas de $0,1 \mathrm{~mL}$ e 1,0 $\mathrm{mL}$ para tubos contendo $10 \mathrm{~mL}$ de caldo Rappaport Vassiliadis (RV) e caldo Tetrationato (TT), e incubados a $41,5 \pm 1{ }^{\circ} \mathrm{C}$, em banho-maria e $37 \pm 1{ }^{\circ} \mathrm{C}$, durante $24 \mathrm{~h}$, respectivamente. No plaqueamento seletivo e diferencial alíquotas dos meios RV e TT foram estriadas, por esgotamento, em placas contendo Agar Xilose-Lisina Desoxicolato (XLD) e Ágar Entérico Hecktoen (HE) e incubadas a $37 \pm 1{ }^{\circ} \mathrm{C}$ por $24 \mathrm{~h}$. Ao término da incubação as colônias suspeitas foram submetidas aos testes bioquímicos para confirmação, onde foram inoculadas em Ágar Tríplice Açúcar e Ferro (TSI), Ágar Lisina e Ferro (LIA) e Caldo Ureia, incubadas a $37 \pm 1{ }^{\circ} \mathrm{C}$ por $24 \mathrm{~h}$. 


\section{Resultados e Discussão}

Do levantamento realizado entre as doceiras localizadas na cidade de Pelotas - RS averiguou-se três empresas produtoras de doces cristalizados de frutas.

Essas doceiras possuem tradição na produção de frutas cristalizadas em Pelotas - RS possuindo entre 35 e 76 anos de atividade no mercado.

A Figura 1 apresenta a avaliação das empresas produtoras de doces de frutas cristalizados de Pelotas - RS quando questionadas a respeito de como veem o mercado atual de cristalizados de frutas.

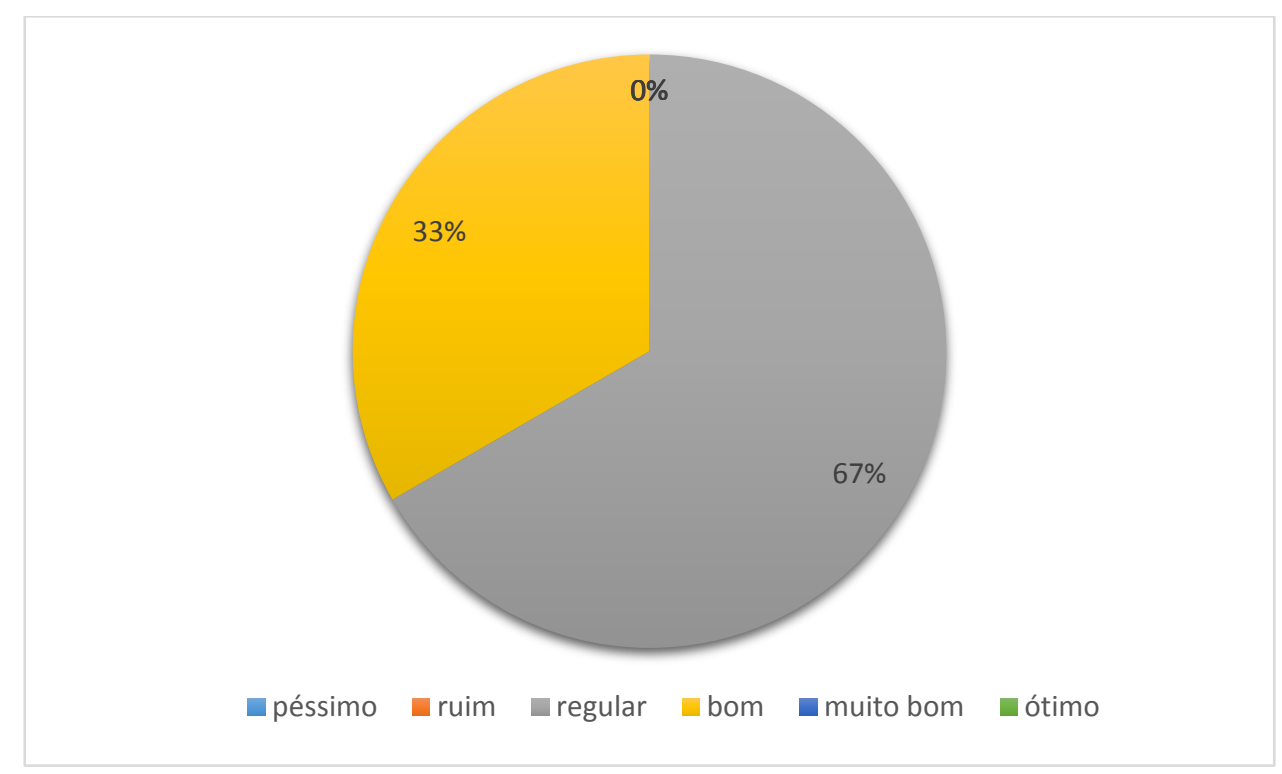

Figura 1. Avaliação das empresas produtoras de doces de frutas cristalizados de Pelotas-RS frente à situação do mercado atual.

Conforme demonstra a Figura 1, 33\% indicaram o mercado atual como bom e 67\% como regular, apontando como principais justificava "estação do ano", o "período de férias" e o fato de se estar "constantemente adaptando-se".

De acordo com o questionário aplicado, nenhumas das três empresas produtoras de doces cristalizados avaliados pertencem a Associação das Doceiras de Pelotas e consequentemente não possuem o selo de Indicação de Procedência. Questionadas quanto aos motivos de não se associarem a falta de oportunidade foi a principal alegação indicada.

A Associação tem como objetivo fortalecer o setor doceiro da região, proteger o legado das receitas de doces tradicionais, estimular a inovação e desenvolvimento das empresas do setor e proteger a marca que leva o nome de Doces de Pelotas. Desta forma, o principal serviço oferecido aos associados é incentivar e impulsionar o crescimento das empresas que compõe a Associação, tanto no que diz respeito à comercialização dos produtos de seus associados como na profissionalização dos mesmos, bem como o acesso a cursos que visem melhorar seus produtos e ajudem na qualificação das mesmas (OLIVEIRA, 2013)

Em relação ao conhecimento e interesse em adquirir o selo de Indicação de Procedência para frutas cristalizadas, somente uma doceira disse não conhecer e não ter interesse no selo. 
O doce cristalizado de fruta é o único doce autorizado pelo INPI que não usufrui da utilização do selo IP, isso se deve ao fato de nenhuma das empresas produtoras pertencerem a Associação Doce Pelotas, o que é exigência, impossibilitando as mesmas de obterem conhecimento e orientações necessárias para os procedimentos de obtenção do selo, uma vez que há diversos requisitos exigidos pelo INPI para a caracterização dos Doces de Pelotas e concessão do mesmo.

No processo de Indicação Geográfica é necessário delimitar as características dos produtos. No caso dos Doces de Pelotas, foram realizadas caracterizações quanto aos ingredientes que podem conter nas receitas, proibições de alterações da receita, o formato em que cada doce deve ser apresentado, sabor e textura que devem possuir, aspectos nutricionais e o tempo e forma de conservação. Quaisquer alterações de acordo com as normativas estabelecidas o produto é considerado descaracterizado, não representando os tradicionais Doces de Pelotas (ASSOCIAÇÃO DOS PRODUTORES DE DOCES DE PELOTAS, 2012).

Apesar de terem obtido o reconhecimento da indicação de procedência pelo INPI, as sociedades empresárias têm dificuldades de explorar o potencial do instrumento. Essa situação pode decorrer da limitação da concepção do modelo de negócio, relacionado aos doces de confeitaria e frutas, bem como da existência dos concorrentes que apresentem escala de produção e os concorrentes informais, que inserem os doces no mercado a um preço relativamente menor. Como são pequenos produtores, as economias de escala e de escopo são restritas, dada a capacidade de produção, bem como a de exportação dos doces para regiões distantes devido à fragilidade do produto (PERALTA et al., 2016).

De acordo com Marchi, Patias e Kneipp (2009) há um agrupamento de produtores de doces atuantes na região de Pelotas que apresentaram dificuldades em se adequar às propostas da IP devido à cultura organizacional, haja vista a informalidade que vivenciam.

Em relação a qualidade dos produtos analisados, e sua conformidade com os parâmetros da legislação podemos verificar os resultados obtidos nas determinações físico-químicas na Tabela 1.

Tabela 1. Resultados das análises físico-químicas realizadas em amostras de figo cristalizado produzido por doceiras de Pelotas - RS.

\begin{tabular}{ccccc}
\hline Amostra* $^{\star}$ & Umidade (\%) & $\mathrm{pH}$ & $\begin{array}{c}\text { Sólidos Solúveis } \\
\text { Totais ( }{ }^{\circ} \text { Brix) }\end{array}$ & $\begin{array}{c}\text { Acidez em ácido } \\
\text { cítrico (\%) }\end{array}$ \\
\hline A & $23,2 \pm 1,9$ & $4,40 \pm 0,01$ & $61,6 \pm 1,1$ & $1,40 \pm 0,14$ \\
B & $20,8 \pm 1,5$ & $4,09 \pm 0,01$ & $60,1 \pm 1,3$ & $1,95 \pm 0,20$ \\
C & $20,8 \pm 0,7$ & $4,18 \pm 0,02$ & $62,9 \pm 1,9$ & $1,69 \pm 0,16$
\end{tabular}

*resultados expressam valor médio \pm desvio padrão.

A legislação sobre frutas, em que estão inclusas as frutas cristalizadas, estabelece a umidade máxima de $25 \%$ como o único parâmetro exigido (BRASIL, 1977). Os demais quesitos físico-químicos variam de acordo com a fruta processada.

Conforme demonstra a Tabela 1, as amostras de figos cristalizados apresentaram valores de umidades inferiores a $25 \%$, estando de acordo com o preconizado pela legislação. Valores de umidade baixos são de suma importância para a conservação do produto, pois a presença elevados teores de água, em alguns gêneros alimentícios, 
indica que ele pode trazer riscos para a saúde do consumidor, por criar ambiente propício para a proliferação de micro-organismos (OLIVEIRA et al., 2013).

A literatura mostra que a melhor faixa de $\mathrm{pH}$ para a obtenção de produtos cristalizados de boa qualidade é em torno de 4, já que nessa faixa ocorre, em menor taxa inversão de sacarose, bem como provoca microfissuras nos vegetais, pela hidrólise de pectina da parede celular, o que favorece a penetração do xarope no interior da mesma (RIBEIRO; SABAA-SRUR, 1999).

Os valores de $\mathrm{pH}$ indicados na Tabela 1 apresentaram-se abaixo de 4,5, valor de referência para impedir o desenvolvimento de Clostridium botulinum, segundo Gava (1995), produtos com acidez inferior a 4,5 eliminam a possibilidade de desenvolvimento desses micro-organismos, não havendo assim, a produção da toxina, embora os esporos possam estar presentes e sobreviverem ao tratamento.

De acordo com Aguirre e Gasparino Filho (2002) a concentração de açúcares da solução osmótica é da ordem de 65 a $70{ }^{\circ}$ Brix. A legislação não estabelece limites para sólidos solúveis em frutas cristalizadas.

As três amostras analisadas apresentaram sólidos solúveis totais acima de 60 Brix, valores próximos aos encontrados por Godoy et al. (2005) que estudou a cristalização de albedos cítricos tendo como média 66,03 ${ }^{\circ}$ Brix e por Moura, Souza e Oliveira (2017) que estudou albedo de maracujá cristalizado (67,33 ${ }^{\circ}$ Brix) e melão cristalizado $\left(69,66^{\circ}\right.$ Brix).

De acordo com Oliveira et al. (2013) o figo maduro apresenta 0,20\% de acidez em ácido cítrico, conforme pode-se observar na Tabela 1 os figos cristalizados apresentaram valores de acidez superiores a 1,4\% em ácido cítrico, o que se justifica devido ao aumento da concentração dos íons $\mathrm{H}^{+}$na cristalização.

A Tabela 2 apresenta os resultados para as análises microbiológicas realizadas em amostras de figo cristalizadas produzidas por doceiras de Pelotas-RS.

Tabela 2. Enumeração de Coliformes Termotolerantes (CTT), Estafilococos Coagulase Positiva (ECP), Bolores e Leveduras (BL) e pesquisa de Salmonella sp. em amostras de figos cristalizados produzidos por doceiras de Pelotas-RS.

\begin{tabular}{ccccc}
\hline Amostra & $\mathrm{CTT}\left(\mathrm{NMP} \mathrm{g}^{-1}\right)$ & $\mathrm{ECP}\left(\mathrm{UFC} \mathrm{g}^{-1}\right)$ & $\mathrm{BL}\left(\mathrm{UFC}^{-1}\right)$ & Salmonella sp $^{*}$ \\
\hline $\mathrm{A}$ & $<3,0$ & $<10$ & $<10$ & Ausência \\
$\mathrm{B}$ & $<3,0$ & $<10$ & $<10$ & Ausência \\
$\mathrm{C}$ & $<3,0$ & $<10$ & $<10$ & Ausência
\end{tabular}

NMP g ${ }^{-1}=$ Número mais provável

UFC $\mathrm{g}^{-1}=$ Unidade formadora de colônias

* presença/ausência em $25 \mathrm{~g}$.

A RDC 12/01 estabelece para frutas desidratadas, secas (excluídas as passas), liofilizadas, com ou sem adição de açúcar ou mel, incluindo as cristalizadas ou glaciadas e similares o limite máximo de $10^{2} \mathrm{NMP} \mathrm{g}{ }^{-1}$ para coliformes a $45{ }^{\circ} \mathrm{C}$ e ausência de Salmonella em $25 \mathrm{~g}$ de produto (BRASIL, 2001). Os resultados obtidos na Tabela 2 demonstram que todas as amostras de figos cristalizados encontram-se 
dentro dos padrões microbiológicos exigidos pela legislação vigente. Os resultados obtidos também foram encontrados por Santos et al. (2014) no estudo com pitaias (Hylocereus Polyrhizus) cristalizadas apresentando contagem de coliformes totais e termotolerantes inferiores a 3,0 NMP g ${ }^{-1}$ e ausência de Salmonella em $25 \mathrm{~g}$.

Embora resolução RDC n 12/2001 (BRASIL, 2001) não estabeleça limites aceitáveis para enumeração de bolores e leveduras e Estafilococos coagulase positiva em frutas cristalizadas, elas são de extrema importância, pois ajudam a atestar a aplicação de boas práticas de fabricação e condições higiênico sanitária dos produtos, uma vez que, de acordo com Evangelista (2001), o S. aureus é transmitido facilmente aos produtos, através de focos conservados por limpeza deficiente e do próprio operador, no qual o microrganismo se localiza no seu nariz, boca, pele e especialmente, em ferimentos. Siqueira (1995) indica que a presença de bolores e leveduras viáveis e em índice elevado nos alimentos pode fornecer várias informações, tais como, condições higiênicas deficientes de equipamentos, multiplicação no produto em decorrência de falhas no processamento e/ou estocagem de matéria-prima com contaminação excessiva. De acordo com Pinheiro et al. (2005) a presença de fungos em número elevado são capazes de produzir grandes variedades de enzimas, as quais provocam a deterioração de frutos. Além disso, muitos bolores podem produzir metabólicos tóxicos quando estão se desenvolvendo nos alimentos.

Os resultados da Tabela 2 denotam que as amostras de figo cristalizadas não apresentaram contagem de colônias significativas para bolores e leveduras e Estafilococos coagulase positiva, indicando que além de cumprirem os requisitos exigidos pela legislação vigente, foram processadas dentro das boas práticas de fabricação e condições higiênicas sanitária exigidas para alimentos, não apresentando risco à saúde do consumidor.

O atendimento às Boas Práticas (BP), as condições higiênicas do ambiente em que se comercializam alimentos e o cumprimento das exigências oficiais e legais, são requisitos importantes para a segurança e qualidade dos alimentos (LUNDGREN et al., 2009).

\section{Conclusão}

Com o presente estudo pode-se concluir que as doceiras produtoras de frutas cristalizadas na cidade de Pelotas-RS não pertencem a Associação Doce Pelotas e consequentemente não possuem o selo de Indicação de Procedência (IP), tendo como principais motivos a falta de oportunidade e desconhecimento da certificação. Nos âmbitos físico-químicos e microbiológicos as amostras de figos cristalizados produzidos estão dentro dos parâmetros exigidos pela legislação atual, possuem qualidade e não apresentam risco à saúde do consumidor, tendo assim potencial para a certificação de Indicação Geográfica e obtenção do selo de Indicação de Procedência.

\section{Referências}

AGUIRRE, J.M.; GASPARINO FILHO, J. Desidratação de frutas e hortaliças. Campinas: ITAL, 2002. 205p.

ASSOCIAÇÃO DOS PRODUTORES DE DOCES DE PELOTAS. Associação. Online. Available from: <http://docesdepelotas.org.br/site/associacao/>. Accessed: Aug. 28, 2018. 
BRASIL. Agência Nacional de Vigilância Sanitária. Resolução n¹5, de 1977. A Comissão Nacional de Normas e Padrões para Alimentos, em conformidade com 0 disposto no capítulo V, artigo 28, do Decreto-Lei $n^{\circ}$ 986, de 21 de outubro de 1969, resolve estabelecer o padrão de identidade e qualidade para frutas cristalizadas e glaceadas. Diário Oficial [da] República Federativa do Brasil, Poder Executivo, Brasília, DF, 15 jul. 1977. Seção 1, p.61. Online. Available from: $<$ https://www.jusbrasil.com.br/diarios/3237238/pg-61-secao-1-diario-oficial-da-uniaodou-de-15-07-1977> Accessed: June. 24, 2018.

BRASIL. Lei $n^{\circ}$ 9279, de 14 de maio de 1996. Regula direitos e obrigações relativos à propriedade industrial. Com alterações estabelecidas pela Lei $n^{\circ} 10.196$ de 14 de fevereiro de 2001. Regulamentada pelos Decretos $n^{\circ} 2.533$ de 16 de abril de 1998, e 3.201 de 06 de outubro de 1999. Diário Oficial [da] República Federativa do Brasil, Poder Executivo, Brasília, DF, 15 mai. 1996. Seção 1, p.8353. Online. Available from: <https://www.planalto.gov.br/ccivil_03/leis/I9279.htm> Accessed: June. 24, 2018.

BRASIL. Ministério da Saúde. Agência Nacional de Vigilância Sanitária. Resolução RDC n. 12, 2 de janeiro de 2001. Aprova o regulamento técnico sobre padrões microbiológicos para alimentos. Diário Oficial [da] República Federativa do Brasil, Poder Executivo, Brasília, DF, 10 jan. 2001. Seção 1, p. 45-53. Online. Available from: $<$ https://www.jusbrasil.com.br/diarios/5845998/pg-82-diario-oficial-do-estado-deroraima-doerr-de-05-01-2004>. Accessed: Dec. 12, 2018.

CHIATTONE, M.V. et al. A importância do evento Fenadoce para a cidade de PelotasRS e a percepção dos visitantes sobre $20^{a}$ edição. In: SIMPÓSIO DE PESQUISA EM TURISMO DO MERCOSUL, 7., 2012, Caxias do Sul, RS. Anais... Caxias do Sul: Universidade de Caxias do Sul, 2012. p. 1-16.

EVANGELISTA, J. Tecnologia de alimentos. São Paulo: Atheneu, 2001. 690 p.

GAVA, A.J. Princípios de tecnologia de alimentos. São Paulo: Nobel, 1995. 233p.

GODOY, R.C.B. et al. Estudo de compotas e doces cristalizados elaborados com diferentes albedos cítricos. Boletim do Centro de Pesquisa e Processamento de Alimentos, Curitiba, v. 23, n. 1, p. 95-108, jan./jun. 2005. Disponível em: https://revistas.ufpr.br/alimentos/article/view/1280 >. Acesso 18 nov. 2018.

INSTITUTO ADOLFO LUTZ (São Paulo). Métodos físico-químicos para análise de alimentos. São Paulo: Instituto Adolfo Lutz, 2008. 1020 p.

INSTITUTO DO PATRIMÔNIO HISTÓRICO ARTÍSTICO E NACIONAL. Pelotas (RS) recebe certificado de Patrimônio Cultural. Online. Disponível em: $<$ http://portal.iphan.gov.br/noticias/detalhes/4675/pelotas-rs-recebe-certificado-depatrimonio >. Acesso 01 nov. 2018.

MARCHI, J.J.; PATIAS, T.Z.; KNEIPP, J.M. O pólo de doces de Pelotas-RS sob a perspectiva da rede de valor: possibilidades estratégicas. In: ENCONTRO NACIONAL DE ENGENHARIA DE PRODUÇÃO. 24., 2009, Salvador, BA. Anais eletrônicos... Salvador: $\quad$ Enegep, $2009 . \quad$ Online. Disponível em: <http://www.abepro.org.br/biblioteca/enegep2009_TN_STO_097_658_14004.pdf >. Acesso 15 jan. 2019.

MOURA, A.G.C.; SOUZA, R.L.A; OLIVEIRA, E.N.A. Elaboração e caracterização físico-química e sensorial de casca de melão e albedo de maracujá cristalizados. Tecnologia \& Ciência Agropecuária, João Pessoa, v.11, n.1, p.77-81. 2017. Disponível em: <https://revistatca.pb.gov.br/edicoes/volume-11-2017/v-11-n-1-marco2017/tca11112.pdf>. Acesso 28 dez. 2020. 
OLIVEIRA, T.A. et al. Qualidade química do doce de figo maduro em calda. In: JORNADA CIENTÍFICA E TECNOLÓGICA E $2^{\circ}$ SIMPÓSIO DE PÓS-GRADUAÇÃO DO IFSULDEMINAS, 5, 2013. Inconfidentes. Anais eletrônicos... Inconfidentes: Instituto Federal Sul de Minas, 2013. Online. Disponível em: <https://jornada.ifsuldeminas.edu.br/index.php/jcinc/jcinc/paper/viewFile/332/117>.

Acesso 01 nov. 2018.

PERALTA, P.P. et al. A Indicação de Procedência como instrumento de diferenciação: o caso do Doce de Pelotas. Redes (St. Cruz Sul, Online), Santa Cruz do Sul, v. 21, n. 2, p. 319 - 343, maio/ago. 2016.

PINHEIRO, N.M.S. et al. Avaliação da qualidade microbiológica de frutos minimamente processados comercializados em supermercados de Fortaleza. Revista Brasileira de Fruticultura, Jaboticabal, v. 27, n. 1, p. 153-156, abr. 2005. https://doi.org/10.1590/S0100-29452005000100040.

RIBEIRO, M.S.; SABAA-SRUR, A.U.O. Saturação de manga (Mangifera indica L.) var. rosa com açúcares. Ciência e Tecnologia de Alimentos, Campinas, v. 19, n. 1, p. 118-122, jan./abr. 1999. https://doi.org/10.1590/S0101-20611999000100021.

SANTOS, A.S. et al. Elaboração e caracterização microbiológica de pitaias (Hylocereus Polyrhizus) cristalizadas. In... CONGRESSO LATINOAMERICANO DE MICROBIOLOGIA E HIGIENE DE ALIMENTOS - MICROAL, 12, 2014, São Paulo, SP. Anais... São Paulo: Editora Blucher, 2014, p. 267-268.

SEBRAE. Indicações Geográficas Brasileiras. Disponível em <http://www.sebrae.com.br/Sebrae/infograficos/livroanimacao/\#/q/17>. Acesso em: 27 jul. de 2018.

SILVA, N. et al. Manual de métodos de análise microbiológica de alimentos. 3 ed. São Paulo: Ed. Varela, 2007. 552p.

SIQUEIRA, R. S. Manual de microbiologia de alimentos. Brasília: Embrapa, SPI, 1995. 156p.

\section{Agradecimentos}

Ao curso de Especialização em Ciência dos Alimentos pela oportunidade de realizar este trabalho.

\section{Autores}

Laís Rössler Rech ${ }^{1, *}$, Mírian Ribeiro Galvão Machado²

1. Curso de Pós-graduação Lato Sensu em Ciência dos Alimentos, Centro de Ciências Químicas, Farmacêuticas e de Alimentos, Universidade Federal de Pelotas, Campus Universitário, Caixa Postal, 354, 96010-900, Pelotas, RS, Brasil.

2. Centro de Ciências Químicas, Farmacêuticas e de Alimentos, Universidade Federal de Pelotas, Campus Universitário, Caixa Postal, 354, 96010-900, Pelotas, RS, Brasil.

* Autor para correspondência: laisrech@hotmail.com 